\title{
Effective Implementation Strategy of Humanities Quality Education for Higher Vocational Students in the Age of New Media Era
}

\author{
Xue-Mei Wang
}

\begin{abstract}
The content of humanistic literacy is characterized by diversification and abstraction. It is the essence preserved in the development of human culture and the pursuit of a higher spiritual realm while people put their material life aside. In recent years, the Chinese government has provided political supports for the healthy and rapid development of higher vocational education, therefore the future outlook of higher vocational education are very positive. However, many higher vocational colleges have neglected the importance of humanistic literacy in the training of talents, resulting in the lack of comprehensive quality of students, which has limited the healthy development of students' personality, eventually leading to low social adaptability and hindered the comprehensive development of students. This paper takes higher vocational colleges as an example, analyzes the problems and solutions in the education of humanistic literacy in higher vocational colleges, and aims to provide future references for the reform of higher vocational education.
\end{abstract}

Index Terms-New media era, higher vocational colleges, students' cultural literacy, implementation strategy.

\section{INTRODUCTION}

Humanistic literacy refers to a person's inner spiritual quality. Its composition includes various factors such as emotions, ideas, and knowledge, reflecting human moral quality, values, personal cultivation, ways of thinking, and outlook on life. Today, China has entered the era of new media, the power of social media has sprung up, and it is characterized by over-entertainment and commercialization. While gaining sensory experience, the nature of information subject has not been given enough attention, leading to the commercialization of the mass media, which greatly reduces the educational function of the mass media. The concept of humanistic literacy is mainly aimed at students, but many students do not receive corresponding humanistic literacy education in their program. Therefore, in view of the above situation, higher vocational education must make changes, and take improving students' humanistic literacy as the guiding ideology, use new media as the main medium, so as to improve students' comprehensive humanistic [1]. Through the implementation of students' humanistic literacy education, higher vocational colleges can enable students to establish a

Manuscript received January 10, 2019; revised July 19, 2019.

Xue-Mei Wang is with Yunnan College of Tourism Vocational, Kunming, 650221, China (e-mail: 2364708870@qq.com). positive outlook on life and values, improve students psychological tolerance in the face of setbacks, cultivate students' excellent moral qualities; Establish students' concept of home country, enhance their sense of social responsibility, and comprehensively improve students' comprehensive quality and interpersonal relationship processing ability to adapt to social development [2]; Improve students' dialectical understanding of traditional culture and new knowledge, so that students can build a spirit of excellence and courage to face difficulties, overcome difficulties in their study, life and future work, and make outstanding contributions to the country and society. From the above content, the importance of humanistic literacy education is not difficult to be discovered. Therefore, in the training of talents in higher vocational colleges, the role of humanistic literacy education must be exerted, so as to cultivate and improve students' humanistic qualities.

\section{THE COGNITION OF HuMANistic Literacy}

\section{A. The Concept of Humanistic Literacy}

Humanistic literacy mainly refers to the exploration of the meaning and value of human existence. In essence, it is a comprehensive literacy including optimistic and positive attitudes towards life, basic moral literacy, human standards and correct value orientation. Humanity literacy is a pursuit of the supreme spiritual realm. With sensibility as the starting point, it provides a freer spiritual environment, ideological emancipation and individuality for human emotions [3]. In summary, humanistic literacy takes people's values, feelings, and aesthetics as the norms of all thoughts and actions, and ultimately achieves the goal of a higher spiritual pursuit.

\section{B. The Connotation of Humanistic Literacy}

Basically, humanistic literacy consists of three elements: human knowledge, spirit and behavior. It is based on a certain knowledge reserve, and then acquires certain knowledge and enhances the individual's spiritual realm. Humanistic knowledge refers to all humanities knowledge formed and developed in human society since the beginning of its birth; Humanistic spirit mainly refers to an attitude that people look at objective things and the laws governing the development of things through a series of studies; Human behavior refers to the practice of putting people's objective understanding of society and nature's truth-seeking and beauty-seeking into practice and giving them an objective understanding of their behavior under the guidance of humanistic knowledge and humanistic spirit [4]. 


\section{Status Quo OF THE Humanities Quality OF STUDENTS AND TEACHERS IN HIGHER VOCATIONAL COLLEGES}

In higher vocational colleges, teaching activities are mainly composed of two different subjects, students and teachers, they are interrelated and affect each other. Therefore, if the humanities quality education is implemented in higher vocational colleges, the implementation environment and the challenges that must be measured carefully to lay the foundation in higher vocational education.

\section{A. Lack of Humanistic Knowledge among Higher Vocational Students}

Students who are enrolled in higher vocational colleges have better basic knowledge and practical skills, but have a low level of understanding of humanities knowledge. Due to the single knowledge structure and the lack of basic humanities knowledge among higher vocational college students, it is difficult for them to realize the comprehensive development. According to the latest relevant surveys, the mastery of humanities knowledge of students in higher vocational colleges generally stays at the level of middle school and high school. Therefore, in the teaching process of higher vocational colleges, the malformation of the knowledge structure has caused problems such as the low level of humanistic knowledge of students and the overall low overall quality of students, so that after entering the society, it is difficult for students to adapt to the various requirements of the society for high-level talents, which also limits their ability to play subjective and the cultivation and improvement of independent thinking skills [5].

\section{B. Poor Humanistic Quality in Higher Vocational Teachers}

From the perspective of the overall quality of teachers in higher vocational colleges, teachers' technical basic knowledge is more fully mastered and professional skills are more practical, however, Higher Vocational college lacks professional teaching forces in the area of humanities quality education, majority of teachers have a low level of social etiquette. Mainly characterized by narrower knowledge and single knowledge structure. base on the survey, $92 \%$ of professionals who demonstrate a decent level of social etiquette are self taught through sources such as internet, books, and TV education, $8 \%$ voluntarily participate in relevant trainings in effort to be certified in the area of humanities equalitya education. Many teachers in higher vocational colleges are generally busy in teaching and caring for their families. They do not have much time to enrich their minds and broaden their knowledge. Some teachers even solidify their thinking patterns and believe that it is a waste of time to learn knowledge other than their own fields, thereby not trying to make any changes to themselves and the form of teaching. The above two situations have caused the narrow knowledge of higher vocational teachers.

IV. ThE NECESSITY OF IMPLEMENTING HuMANITIES QuALiTy EdUCATION IN Higher Vocational COLLEGES

\section{A. Urgent Requirements for the Development of Modern Society}

Nowadays, the demand for talents in society is not only limited to the mastery of professional knowledge and skills, but also embodied in the possession of comprehensive literacy. For example, etiquette education plays an important role in improving the service quality in the service industry. According to recent study, $12 \%$ of interviewed enterprises rated themselves excellent in the area of employee etiquette, $34 \%$ reported good employee etiquette, and $51 \%$ revealed that employees demonstrate average level of social etiquette, $1 \%$ of companies rated themselves very poor, and $2 \%$ of companies are unclear about the employee etiquette. The reasons for the low level of social etiquette among employees are mainly due to the lack of school education, insufficient family education, and the influence of bad social atmosphere [6]. However, due to the division of majors in higher vocational colleges is too detailed, professional teachers only master the knowledge and skills of the profession resulting in students' lack of mastery of humanistic knowledge. The teaching mode of higher vocational colleges can not meet the demands of contemporary society for talents. Therefore, the reform of education system is urgent.

\section{B. Requirements for the Improvement of Students' Overall Quality}

Because the form of evaluation in China still belongs to exam-oriented education, over-emphasizing the proficiency of knowledge and skills mastery, and adopting intensive training and excessive learning methods to align students' learning aspects with exams, resulting in students being difficult to exert subjective initiative, which limits the cultivation and individualized development of students' hobbies and interests. In fact, in the high school stage, the liberal art and the science are separated prematurely, leading students to focus on the opposite aspects of the liberal art and the science, and this situation will continue until the university. Therefore, the lack of humanistic literacy education caused by the emphasis on liberal arts and science in students during the middle school period needs to be compensated back during the period of higher vocational education.

\section{Urgent Requirements for the All-Round Harmonious Development of Students}

The all-round development of people mainly refers to the coordinated development of people in intellectual, physical, aesthetics and labor education. Humanistic literacy education is an effective way to realize the all-round development of people, and it is of great significance to the cultivation and improvement of people's comprehensive quality. At the same time, the improvement of humanistic literacy is also an important measure of social development and progress. The implementation of humanistic literacy education in higher vocational colleges can effectively eliminate the cognitive bias caused by the division of the liberal art and the sciences, expand the knowledge and vision of students, and enable students to have rich humanistic knowledge beyond professional knowledge and skills. Therefore, while promoting individualized development, the students' 
potential can be maximized.

\section{Cultivation of Students' Innovative Thinking}

Innovation is the main driving force for social development and progress. The concept of "mass entrepreneurship and the multitude innovation" has long been deeply rooted in the hearts of the people [7]. Humanistic literacy education mainly cultivates students' thinking ability, so that they treat and observe things with divergent and diversified thinking, thus complementing the natural sciences, cultivating students' diversified knowledge structure, and improving students' innovative thinking and innovation ability. Therefore, the cultivation of students' humanistic literacy is closely related to the students' professional achievements in the future, and it also lays a solid foundation for the development of creative activities.

\section{ANALysis OF THE CHALLENGES OF HuMANITIES QUALITY EDUCATION}

\section{A. Changes in Student Resources}

On the road of continuous realization of modernization reform and sustained improvement of the education system in China, the source of students in higher vocational colleges has undergone tremendous changes. With the reform of higher vocational education, the source of students includes normal high school graduates and vocational school three-year students and five-year students. Facing the change of students' sources, the adjustment of higher vocational education has become one of the most challenging problems. According to the latest survey results, students in vocational schools and five-year schools have already experienced serious quality and unhealthy lifestyles. Most students in vocational schools and five-year junior high schools have an uncontrollable obsession with the Internet. With the progress of society, mobile phones have gone deep into their day to day living. Whether they are in class or not, students are almost at zero distance from mobile phones. It is not enough to use the "heads-down tribe" to describe mobile phone control. The popularity of online applications has exacerbated the quality problems of professional students. In the past, people's concerns about the post-90s only involve issues such as being overly spoiled by parents and lack of independence. Nowadays, due to the adverse effects of mobile phones and the Internet, the humanities quality of the post-95s students is becoming more vulgar. For example, as early as one month before Christmas in 2018, it is enthusiastically promoted and students are preparing for Christmas However, students know little about the meaning of traditional festivals in our own country, which is not a lack of knowledge, but a lack of understanding of traditional culture and hometown folk customs. The vast majority of the post-95s are the only children. These children have individuality and self-centeredness, and the large group of schools can make them form a collective consciousness and have a clear understanding of their own deficiencies. As for the change of student source channels, how to teach students in accordance with their aptitude and develop high-level students into excellent talents is an important issue to be solved.

\section{B. Internationalization}

With the implementation of China's "The Belt and Road" initiative, the development of enterprises has also made rapid progress. Under the new economic norms, many enterprises have stepped out of the country and cooperated with foreign companies. Therefore, higher vocational colleges must consider the internationalization of education. In this context, higher vocational colleges need to expand their teaching horizons, train students with an international perspective, and require students' theoretical study and knowledge application ability to meet the standards of talent cultivation with international standards, so as to reserve talents for the society. Compared with China, foreign countries pay more attention to humanistic literacy. European countries believe that humanistic literacy is crucial for student development.

Lawrence Katz, the labor economist at Harvard University, believes that the technological returns of society tend to be balanced, and humanistic education is the key to social level improvement. The development of society is not only the development of the economy, but also the demand for the quality of talents is constantly improving. Nowadays, talents who have certain value to the society must have the ability to communicate, cooperate, and work. If one wants to gain a foothold in society, the humanistic literacy is fundamental. This also fundamentally explains that humanistic literacy is the embodiment of competitiveness among various countries. Therefore, whether it is to participate in international competition, promote international education, or to cultivate "going global" international talents for domestic enterprises, higher vocational colleges must further strengthen the humanities quality education of students.

\section{Network Influence}

The reason why China pays more attention to humanistic literacy is that the rapid development of society makes people's psychology impetuous, and the humanities quality discipline is regarded as poor economic returns, so there are more voices to question the functions of humanities quality. Especially in the era of continuous updating of network technology, to a large extent, the cognitive scope and channels of social groups are changed, leading to great changes in people's problem thinking methods and life concepts. These changes include the weakening of the emphasis on humanistic literacy, and the increasing impacts and challenges faced by humanistic literacy education in higher vocational colleges. In the context of complex society, the construction of the network environment is necessary, the purification of campus networks needs to be strengthened, and the importance of improving humanistic literacy education becomes more and more prominent.

\section{Humanities QuALITY EDUCATION STRATEGY FOR Higher VocATIONAL STUDENTS}

As a key trade-off indicator for comprehensive development, the basic nature of humanistic literacy determines its importance and reflects the degree of civilization of society. Humanistic literacy is like the root of 
growth, it is said that the thicker the leaves, the deeper the root. The growth and health of a person is the embodiment of humanistic literacy. For students in higher vocational colleges, humanistic literacy is the most competitive quality in society. As we all know, humanistic literacy is not innate, it depends on education. It is the result of the internalization of the campus environment and the internalization of humanistic knowledge. In higher vocational colleges, humanistic literacy education should be infiltrated into the curriculum, and the curriculum should be internalized into the personality charm of students, thereby the humanistic literacy is improved, and becoming the relatively stable internal character of students.

\section{A. Play the Main Channel Function of the Classroom}

The learning and absorption of all knowledge is carried out in the classroom, and humanities knowledge is also learned in the classroom. Therefore, as the main channel for students to carry out knowledge learning, teachers should fully understand the classroom as the main channel for students to absorb humanities knowledge, and use the functions of the classroom to maximize the use of the classroom. Schools should encourage teachers with special skills to teach as much as possible, so that teachers can infiltrate humanities knowledge into daily teaching while carrying out professional knowledge and skills transfer, so that students can not only master professional knowledge and skills in daily classroom learning, but also improve their humanistic qualities and comprehensive ability through the teaching by teachers.

\section{B. Open a Humanities Education Course}

After the end of the Second World War, foreign universities have realized the importance of humanistic literacy education and the disadvantages of lack of humanistic literacy education for talent training. For example, Harvard University and Oxford University have already begun the development and application of humanities quality education courses. It was not until the end of the 20th century that China put the opening of the humanities quality education curriculum on the agenda and conducted a preliminary attempt to educate the humanities quality. In the formulation of talent training programs, some higher vocational colleges have added humanities quality courses, mainly to the study and expansion of Chinese traditional culture and history. Through the study of traditional culture and etiquette, the principle of "on going on in the world" is cultivated, and the correct outlook on life and values are established. Not only that, the development of humanities quality education curriculum is not only important for the implementation of socialist core values, but also promotes the improvement of the quality of higher education throughout the country. In humanistic literacy education, the important role of socialist core values should be fully exerted.

\section{Build a Good Campus Culture Environment}

Campus culture belongs to the school's cultural soft power, and it is also the embodiment of the school's historical and cultural thickness, it undertakes the task of subtly affecting students' world outlook on life, and it is also an important carrier for practicing the comprehensive concept of educating people. Through the construction of a healthy and positive campus culture, the cohesiveness of teachers and students in higher vocational colleges has been improved, and the comprehensive development of teachers and students has been promoted. Higher vocational colleges should pay more attention to the construction of campus cultural environment, because campus culture has an impact on students' way of thinking, moral values, value orientation and behavior. Campus culture can reflect the formulation and implementation of the design of campus architecture and landscape, school motto and school rules, transforms the external requirements of students into the inner quality of students, and implement the quality education of humanities in the way of campus culture environment. The purpose is not only to promote the improvement of students' humanistic literacy, but also to enable the whole school teaching staff to motivate them to continue to advance under the influence of good campus culture, and ultimately achieve the purpose of improving the quality of all staff and staff in higher vocational colleges, thus creating a high-school campus culture environment for all people to learn.

\section{Conduct Diverse Campus Cultural Activities}

On the basis of building a good campus culture environment, the development of diversified campus culture activities can enrich the students' after-school life in higher vocational colleges, while the students' moral qualities are improved and the principles of living in the world are learned. There is no doubt that the main body of campus cultural activities is students, and they are externalized into various forms of student societies that are managed and organized by students. Compared with the classroom form, the club activities are more free, the subjects are more extensive, and closer to the student life, so for the students of higher vocational colleges, the club activities are often more attractive, providing students with the opportunity to show themselves, promoting the individualized development of students and providing a platform for the improvement of students' personality. Higher vocational colleges can hold campus culture festivals, through the free organization of students, students can improve their overall quality and execution ability, and tap their potentials in recreational activities and promote their all-round development.

\section{E. Play the Role of New Media}

With the rapid development of network information technology, the concept of new media is gradually becoming familiar with people. Compared with traditional media, new media utilizes a variety of information technologies and mobile terminals to provide users with real-time information. According to relevant information, the new media has been applied to the daily teaching research by many higher vocational colleges in China, and the existing colleges have achieved good application results. As a recipient of new media information, students in higher vocational colleges have a large base and strong ability to accept. Therefore, in the new media era, the reform of higher vocational education has become an urgent task. The new media carries a new culture into the higher vocational colleges, which has a positive effect on the improvement of students' humanities 
quality. New media resources are abundant, but this has also become a disadvantage of new media. Although the new media resources are abundant, the quality is mixed. Therefore, in the application of new media in humanities quality education in higher vocational colleges, it is necessary to first screen new media resources and eliminate negative and decadent new media resources to make it possible to take advantage of the new media. Through the establishment of the school website and the WeChat public platform, higher vocational colleges may update the school's dynamics in real time, and promote the students' style by promoting students to publish articles on the platform, and regularly update the school website and related articles of WeChat public account, thereby the knowledge of the students is expanded and the overall healthy development of the students is promoted.

\section{F. Improve the Humanities Quality of Teachers}

There's an old adage that says: "The teacher, one who could propagate the doctrine, impart professional knowledge, and resolve doubts", only by this sentence, the famous poet Han Yu of the Tang Dynasty has fulfilled the duties and obligations of the teacher. It is a brilliant summary of the function of the teacher. As an unchanging educational philosophy, this sentence has been passed down to the present day. In order to do a good job of the people's teachers, the teachers themselves must first have a good moral quality, adhere to the learning philosophy of lifelong learning, constantly improve themselves in work and life, and improve their humanistic literacy and level of imparting knowledge and educating people. Therefore, teachers should not only be proficient in the knowledge and skills of their own professional fields, but also possess humanities knowledge such as art and psychology, enhance the internal cultivation of teachers, and guide students to actively learn and answer questions for their own personality, and lay a solid foundation for the future development of students. In addition, higher vocational colleges should actively carry out teacher training activities and research activities to improve the overall quality of teachers.

\section{CONCLUSION}

The humanistic literacy of a person largely determines the length and breadth of the path of life to a large extent. Only by continuously improving one's humanistic qualities, human society will continue to move forward. Higher vocational colleges mainly train technical talents for the society, and should strengthen the education of humanities quality and improve the education system of higher vocational colleges. At present, in the era of economic globalization, people's personality is high, values and outlook on life are also diversified, so it is necessary to reform the education of higher vocational colleges, and to proceed from its own actual situation, keep up with the trend of the times, deliver high-quality talents to the society, and make more contributions to the implementation of the socialist core values and the realization of the dream of a strong country.

\section{CONFLICT OF INTEREST}

Authors have no conflict of interest to declare.

\section{AUTHOR CONTRIBUTIONS}

Xue-Mei Wang conceived and designed the study and independently wrote the paper.

\section{REFERENCES}

[1] B. Y. Jin and D. F. Li, "Research on the strategies of humanity quality education and cultural confidence in higher vocational colleges Taking Changzhou higher vocational colleges as an example," Vocational \& Technical Education Forum, no. 17, pp. 45-48, May 2017.

[2] B. Y. Liu and W. Qian, "Research on the pattern of humanity quality education in higher vocational colleges," Heilongjiang Researches on Higher Education, no. 9, pp. 128-130, Sep. 2016.

[3] H. M. Jin, "The problems and countermeasures of implementing humanistic literacy education in Chinese teaching in higher vocational colleges," Theory and Practice of Education, no. 9, pp. 20-21, Mar. 2017.

[4] X. Sun and R. Dong, "Analysis on the construction strategy of humanities quality in higher vocational colleges," Shandong Social Sciences, pp. 352-354, Dec. 2016.

[5] P. Wu, "The role of Chinese traditional tea culture in the humanities quality and ideological education of today's college students," Fujian Tea, vol. 39, no. 8, pp. 189-190, Aug. 2017.

[6] X. P. Yang, "Research on the demand of offering "tourism service etiquette" courses for tourism majors [J]," Research on the Development of Tourism Vocational Education in the New Era, 2018, pp. 233-237.

[7] J. H. Yu, "Research on innovation of applied writing course teaching method in vocational colleges under the background of new media," Training in China, no. 6, pp. 77-77, Mar, 2016.

Copyright (C) 2019 by the authors. This is an open access article distributed under the Creative Commons Attribution License which permits unrestricted use, distribution, and reproduction in any medium, provided the original work is properly cited (CC BY 4.0).

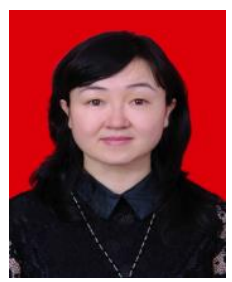

Xue-Mei Wang was born in Kunming, China. She has earned her bachelor degree from Kunming University of Science and Technology. She is currently an associate professor at Yunnan College of Tourism Vocational, Kunming, China. She has been working at the College for more than twenty years. The courses she teaches are humanistic literacy and etiquette. She have been compiled many etiquette textbooks, such as "service and reception etiquette" and "travel service etiquette". Her research interest is in humanistic quality education, and she writes many related articles. 